\title{
Body packers: a plea for conservative treatment
}

\author{
Jacob K. de Bakker • P. W. B. Nanayakkara • \\ L. M. G. Geeraedts Jr. • E. S. M. de Lange • \\ M. O. Mackintosh $\cdot$ H. J. Bonjer
}

Received: 7 April 2011 / Accepted: 2 September 2011 /Published online: 8 October 2011

(C) The Author(s) 2011. This article is published with open access at Springerlink.com

\begin{abstract}
Background The incidence of smuggling and transporting of illegal drugs by internal concealment, also known as body packing, is increasing in the Western world. The objective of this study was to determine the outcome of conservative and surgical approaches in body packers.

Materials and methods Clinical data on body packers admitted to our hospital from January 2004 until December 2009 were collected. The protocol for body packers required surgery when packets were present in the stomach for $>48 \mathrm{~h}$. Outcomes of the conservative and surgical group were assessed and analyzed. Morbidity and mortality were assessed in body packers with drug packets present in the stomach for $<48 \mathrm{~h}$ and in those with gastric packets for $>48 \mathrm{~h}$. Results During the study period, more body packers were treated conservatively. Mortality was $2 \%$ in all patients and was due to intoxication. There were no significant differences of mortality, hospital admission time, and ICU admission time in the compared groups with drug packets in the stomach for less or $>48 \mathrm{~h}$. In $24 \%$ (4/17) of the patients with bad package material, a ruptured drug packet was found during surgery. This resulted in death in only one patient.

Conclusion Drug packets in the stomach for $>48 \mathrm{~h}$ are not an indication for surgery. We recommend that surgery
\end{abstract}

J. K. de Bakker $(\bowtie) \cdot$ L. M. G. Geeraedts Jr.

E. S. M. de Lange $\cdot$ M. O. Mackintosh $\cdot$ H. J. Bonjer

Department of Surgery, VU University medical centre,

De Boelelaan 1117,

Amsterdam, The Netherlands

e-mail: j.debakker@vumc.nl

P. W. B. Nanayakkara

Department of Internal Medicine, VU University medical centre,

De Boelelaan 1117,

Amsterdam, The Netherlands should only be performed in body packers with signs of intoxication or ileus and reserve conservative treatment for all other patients.

Keywords Body packer - Conservative · Surgery · Treatment

\section{Introduction}

Smuggling and transporting of illegal drugs have become more common in the USA and Europe in the past decade. One of the methods used by smugglers is the so-called internal concealment or "body packing" [1]. The first case of smuggling drugs by internal concealment was described in 1975 [2]. Body packing involves swallowing specially prepared packets of a wrapped drug. Insertion of the packets in the rectum or vagina is often referred to as body pushing [3]. Other terms for body packers include swallowers, couriers, and mules [4]. In case of smuggling cocaine, body packers ingest an average of $1 \mathrm{~kg}$ divided into several smaller packages containing 3-12 g each. With the lethal dose of cocaine ranging from 1 to $3 \mathrm{~g}$, rupture of even a single pellet may be fatal.

Initially, drug packets consisted of balloons, condoms, aluminum foil, or latex gloves. However, these first packets often tended to burst resulting in the loss of drugs and subsequent death of the body packer. At present, drug packets are machine produced and therefore uniform in size and weight. These newer packets consist of highly compressed drugs in several layers of latex. While mortality rates up to $56 \%$ were reported in the past, the introduction of these new packets has reduced the chance of rupture and thereby decreased the morbidity and mortality drastically [5-8]. This new type of packaging is a special challenge to custom 
agents and health care professionals because they are not always visible (radio-opaque) on abdominal radiographs [9].

The incidence of body packing is increasing, and as a consequence, surgeons are more frequently confronted with these patients [10]. In the early years, patients presented with symptoms of intoxication and were either too sick for surgery or were dead at presentation. Body packers with opioid toxicity present themselves with depressed mental status, decreased respiration rate, miosis, and decreased bowels sounds. The cocaine toxidrome consists of agitation, hypertension, tachycardia, mydriasis, and diaphoresis. During the last 10 years, more patients have presented with abdominal symptoms such as nausea, discomfort, or bowel obstruction $[10,11]$.

This study was designed to evaluate the efficacy of the protocol we used to diagnose and treat these patients and to determine the necessity to perform surgery.

We further aimed to develop an algorithm for the treatment of body packing, which can be used at any emergency department.

\section{Patients and methods}

We retrospectively collected data on body packers admitted to the department of surgery in our hospital from January 2004 until December 2009. All admissions with the diagnosis of "accidental self-injury" between January 2004 until December 2009 were screened for the diagnosis "body packer" because not all patients with the diagnosis of "accidental self-injury" were body packers. All selected patients were included in this study.

The following data of these patients were recorded: year of presentation, age, sex, date of admission, type of drugs, signs and symptoms at time of presentation, e.g., abdominal pain, vomiting, and agitation, systolic blood pressure, diastolic blood pressure, white cell count, radiological investigation (number of drug packets, localization of the drug packets), treatment, complications of surgery, e.g., fascial dehiscence and wound infection, general complications, duration of admission, mortality, possible stay at the intensive care unit, and medical history.

Wound infection was defined as an incision with purulent drainage. Fascial dehiscence was defined as separation of the abdominal fascia with or without herniating organs.

All patients presented at our emergency department with the suspicion of body packing were treated according our current protocol. The protocol initially in use included frequent monitoring of the vital signs, routine laboratory testing and radiological investigation. Initially, a plain Xray of the abdomen was performed. If the plain X-ray of the abdomen was inconclusive and the radiological localization of the packets was uncertain, a CT scan of the abdomen was performed. This was done especially in patients in which the localization of drug packets in the stomach could not be excluded. Nowadays, there is a new challenge in the radiological investigation of body packers due to the emergence of liquid cocaine, which is less visible on a plain X-ray of the abdomen.

According to our current protocol for the treatment of body packers, surgical removal of drug packets was indicated in case of signs of drugs intoxication (such as tachycardia, anxiety, hypertension, or seizures), ileus, or retention of drug packets in the stomach for $>48 \mathrm{~h}$. Patients who underwent surgery were compared with those who were treated conservatively.

Variables were analyzed with Student's $t$ tests or chisquare tests when appropriate. A $p<0.05$ was considered statistically significant difference. Data were analyzed using SPSS 17.0 for Windows (SPSS, Chicago, IL, USA).

\section{Results}

Between 1 January 2004 and 31 December 2009, 143 body packers were admitted to our hospital. Seventy-nine body packers were treated conservatively, and 64 body packers underwent surgery.

Demographic data are shown in Table 1. The mean age in the conservative group was 33.3 years $(\mathrm{SD} \pm 9.2)$ and 36.3 years $(\mathrm{SD} \pm 9.3)$ in the surgical group. This difference was significant with a $p=0.05$. The conservative group consisted of 55 men and 24 women, while the surgical group consisted of 56 men and eight women.

Between 2004 and 2009, there was no annual increase of the number of body packers admitted to our hospital, although a trend was noted during the first 3 years of our study. More body packers were treated surgically between 2004 and 2006 . However, in the last 3 years of this study, 2007 until 2009, more body packers were treated conservatively (Fig. 1).

The most prevalent smuggled drug in both groups of body packers was cocaine and was found in $73 \%$ of the conservative group and in $91 \%$ of the surgical group. In the remaining patients, drug packets contained heroin or marihuana.

There was no significant difference in the number of packets between both groups with a mean of $58.1 \pm 35.3$ in the surgical group and $48.2 \pm 37.9$ in the conservative group.

Clinical characteristics of the body packers are shown in Table 2.

In the surgical group, there was a significantly higher percentage of patients with abdominal pain than in the conservative group, $53 \%$ versus $31 \%$, respectively $(p=0.001$ ). In the surgical group vomiting was significantly more prevalent at presentation $(20 \%$ vs $13 \%, p=0.011)$. There was no significant difference in systolic and diastolic blood 
Table 1 Demographics

\begin{tabular}{|c|c|c|c|}
\hline & $\begin{array}{l}\text { Conservative } \\
N=79\end{array}$ & $\begin{array}{l}\text { Surgical } \\
N=64\end{array}$ & $\begin{array}{l}p \\
\text { value }\end{array}$ \\
\hline Age (mean $\pm \mathrm{SD})$ & $33.3 \pm 9.2$ & $36.3 \pm 9.3$ & 0.05 \\
\hline Male & 55 & 56 & \\
\hline Female & 24 & 8 & \\
\hline \multicolumn{4}{|c|}{ Interval between ingestion and admission, $n(\%)$} \\
\hline Less than $24 \mathrm{~h}$ & $9(12 \%)$ & $3(5 \%)$ & \\
\hline $24-48 \mathrm{~h}$ & $13(16 \%)$ & $7(11 \%)$ & \\
\hline $49-72 \mathrm{~h}$ & $9(12 \%)$ & $10(16 \%)$ & \\
\hline More than $72 \mathrm{~h}$ & $14(17 \%)$ & $22(34 \%)$ & \\
\hline Unknown & $34(43 \%)$ & $22(34 \%)$ & \\
\hline $\begin{array}{l}\text { Duration of hospital } \\
\text { admission (days) }\end{array}$ & $2[1-3]$ & $7[5.0-14.5]$ & \\
\hline \multicolumn{4}{|l|}{ Year of admission } \\
\hline 2004 & 5 & 14 & \\
\hline 2005 & 5 & 8 & \\
\hline 2006 & 7 & 13 & \\
\hline 2007 & 20 & 12 & \\
\hline 2008 & 10 & 6 & \\
\hline 2009 & 32 & 11 & \\
\hline \multicolumn{4}{|l|}{ Type of drugs } \\
\hline Cocaine & $58(73 \%)$ & $58(91 \%)$ & \\
\hline Heroin & 0 & $3(5 \%)$ & \\
\hline Marihuana & 0 & $1(1 \%)$ & \\
\hline Unknown & $21(27 \%)$ & $2(3 \%)$ & \\
\hline $\begin{array}{l}\text { Number of packets } \\
(\text { mean } \pm \text { SD })\end{array}$ & $48.2 \pm 37.9$ & $58.1 \pm 35.3$ & 0.133 \\
\hline
\end{tabular}

pressure between the two groups. The white cell count was higher in the surgical group (11.0 $\pm \mathrm{SD}$ in the surgical group versus $9.6 \pm \mathrm{SD}$ in the conservative group, $p=0.031$ ).

Data on surgical findings are shown in Table 3.

The indication for surgery was retention of one or more drug packets in the stomach for $>48 \mathrm{~h}$ in 25 patients $(40 \%)$,

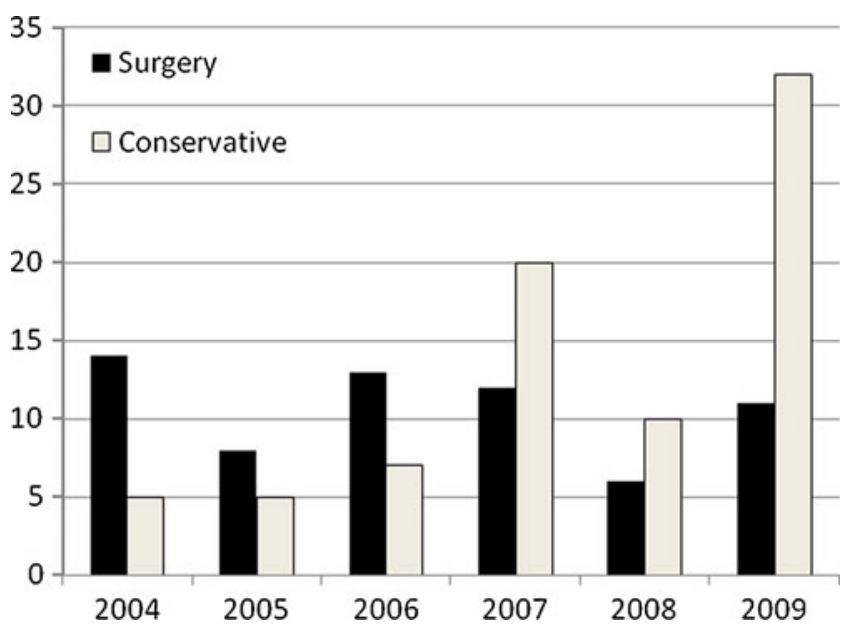

Fig. 1 Surgical and conservative therapy, 2004-2009
Table 2 Clinical characteristics

\begin{tabular}{llll}
\hline & $\begin{array}{l}\text { Conservative } \\
N=79\end{array}$ & $\begin{array}{l}\text { Surgical } \\
N=64\end{array}$ & $p$ value \\
\hline Abdominal pain & $25(31 \%)$ & $34(53 \%)$ & 0.001 \\
Vomiting & $10(13 \%)$ & $13(20 \%)$ & \\
X-boz ileus: yes & 1 & 4 & 0.011 \\
No & 9 & 9 & \\
Agitation & $3(4 \%)$ & $15(23 \%)$ & 0.000 \\
Systolic blood pressure $^{\mathrm{a}}$ & $134.2 \pm 26.5$ & $137.9 \pm 25.3$ & 0.433 \\
Diastolic blood pressure $^{\mathrm{a}}$ & $80.0 \pm 16.9$ & $82.0 \pm 14.6$ & 0.485 \\
Heart rate $^{\mathrm{a}}$ & $79.0 \pm 16.6$ & $91.9 \pm 24.5$ & 0.001 \\
White cell count $^{\mathrm{a}}$ & $9.6 \pm 3.3$ & $11.0 \pm 4.1$ & 0.031 \\
Localization of packets $^{\mathrm{b}}$ & & & \\
Esophagus $_{\text {Stomach }}$ & 0 & 1 & \\
Small Intestine $_{\text {Colon }}$ & 23 & 43 & \\
Rectum & 43 & 35 & \\
\hline
\end{tabular}

${ }^{\mathrm{a}}(\mathrm{Mean} \pm \mathrm{SD})$

${ }^{\mathrm{b}}$ In $42 \%$ of the conservative treated patients, a combination of localization was found. In $63 \%$ of the surgically treated patients, a combination of localization was found

signs of intoxication in 23 patients (35\%), and signs of an ileus in 11 patients (17\%), while five patients $(8 \%)$ had another indication for surgery.

In the surgical group, 10 patients developed a wound infection (16\%) and 10 patients had a fascial dehiscence $(16 \%)$. Five of them had both a wound infection and a fascial dehiscence (8\%). Rupture of drug packets did not occur in any of these patients. Four patients developed anastomotic leakage, which did not lead to mortality in any of these patients. After admission, all patients who had a surgical complication were evaluated in our outpatient department.

Patients with wound infections were admitted longer ( $31 \pm 9.9$ days versus $10 \pm 1.2$ days, $p=0.001)$ and had more packets $(83 \pm 33$ versus $54 \pm 32, p=0.02)$.

Hospital stay was significantly longer in the surgical group with a mean of 7 days compared to a mean of 2 days in the conservatively treated group $(p=0.01)$.

Two surgical patients developed complications: one pneumonia and one urinary tract infection.

Not all body packers who were surgical treated underwent a laparotomy. One patient underwent a thoracotomy due to a rupture of the distal esophagus caused by a drug packet, which led to a left thorax empyema. In the literature, no such case has been described yet. It is unknown if the rupture was caused by vomiting or more directly by the drug packet. This patient survived. 
Table 3 Surgical data

\begin{tabular}{|c|c|}
\hline & $N=64$ \\
\hline \multicolumn{2}{|l|}{ Indication for surgery } \\
\hline Time $>48 \mathrm{~h}$ & 25 \\
\hline Intoxication & 23 \\
\hline Ileus & 11 \\
\hline Other & 5 \\
\hline \multicolumn{2}{|l|}{ Type of surgery ${ }^{\mathrm{a}}$} \\
\hline Gastrotomy & 51 \\
\hline Enterotomy & 25 \\
\hline Colotomy & 37 \\
\hline Bowel resection + stoma & 3 \\
\hline Other & 5 \\
\hline \multicolumn{2}{|l|}{ Complication of surgery } \\
\hline Wound infection & $10(16 \%)$ \\
\hline Facial dehiscence & $10(16 \%)$ \\
\hline Anastomose leakage & $4(6 \%)$ \\
\hline Relaparotomy & $11(17 \%)$ \\
\hline Length of surgery (minutes) & $100[85-130]$ \\
\hline \multicolumn{2}{|l|}{ Antibiotic prophylaxis } \\
\hline Yes & $46(72 \%)$ \\
\hline Unknown & $18(28 \%)$ \\
\hline \multicolumn{2}{|l|}{ Bad quality package } \\
\hline Yes & $17(27 \%)$ \\
\hline No & $47(73 \%)$ \\
\hline \multicolumn{2}{|l|}{ Rupture of drugs packet } \\
\hline Yes & $4(6 \%)$ \\
\hline No & $60(94 \%)$ \\
\hline
\end{tabular}

${ }^{\mathrm{a}}$ In $66 \%$ of the patients, a combination of enterotomies was performed

Mortality in our study was 2\% (3/143 patients). One patient was unsuccessfully resuscitated at presentation at the Emergency Department. The two other deaths were due to intoxication. Both had emergent surgery and were cooled in the intensive care unit to preserve cerebral function. Both patients died within 2 days after surgery.

One of the main purposes of this study was to evaluate the efficacy of the protocol for body packers. Our protocol requires surgery in body packers with proven packets in the stomach for $>48 \mathrm{~h}$, also in absence of any signs of intoxication or ileus. This deadline was chosen arbitrarily. The results of our study showed no significant difference in the outcome of asymptomatic patients with proven drug packets in the stomach with a cutoff point at $48 \mathrm{~h}$. We divided patients with drug packets in their stomach in two groups: one group with packets $<48 \mathrm{~h}$ in the stomach and another group with packets in the stomach for $>48 \mathrm{~h}$. Comparison of these two groups showed no significant difference in mortality $(p=0.78)$, ICU admission time $(p=$ $0.22)$, and hospital admission time $(p=0.12)$. In the group that underwent surgery, no significant differences in wound infection ( $p=0.63)$, fascia dehiscence $(p=1.00)$, anastomotic leakage $(p=0.17)$ or relaparotomy $(p=0.19)$ were found when the same cutoff point of $48 \mathrm{~h}$ was used.

In $24 \%(4 / 17)$ of the patients with bad package material, a ruptured drug packet was found. In only one of those four patients, a ruptured packet caused death.

\section{Discussion}

Smuggling drugs by internal concealment also known as body packing has become more common in the USA and Europe in the past decade. The cause of the increase in body packing is unknown. Our hospital is located nearby Schiphol Amsterdam International Airport and provides health care services to its personnel and travelers. Body packers who are arrested at the airport are transferred to the Schiphol Detention Centre. Those body packers who had signs of abdominal distress or intoxication presented at our hospital. Other body packers reported voluntarily to our emergency department. Worldwide growing knowledge in the treatment of body packers resulted in more conservative treatment compared to surgical treatment, which initially was seen as the only feasible option. This increase in conservative management can also be derived from the low amount of patients we have treated in our hospital during the study period compared to the increasing number of body packers who pass our customs every day.

Body packing is a growing challenge to immigration and customs officers because current packaging is difficult to detect. In the early days of body packing, aluminum foil or tape were used to wrap the drugs, while these radio opaque materials have been progressively replaced by condoms, which escape plain radiographic imaging. All patients in our study had radiologic investigation, but when the presence or localization of drug packets was uncertain, a complementary CT scan of the abdomen was performed. This was done in 26 of the 143 patients (18.2\%). It is likely that the use of CT scan will increase due to the use of non-radio-opaque package materials such as condoms filled with liquid cocaine. Another reason for a more frequent use of a CT scan of the abdomen is the conclusion drawn by Traub et al. who found a higher sensitivity and specificity of a CT scan compared to a plain X-ray of the abdomen for the diagnosis of bowel obstruction [4]. Not all of our patients had a postoperative X-ray to confirm no residual packets although this is recommended by De Beer et al. [10].

The timing of surgery in asymptomatic patients with residual packets in their stomach is controversial, and hence, consensus is lacking. Some authors consider 5 days as sufficient time for the passage of the drug packets [1, 12]; other authors adhere to time that is varying from $27 \mathrm{~h}$ and 7 days $[13,14]$. Our hospital protocol is to perform surgery in patients who have proven drug packets in the 
stomach for $>48 \mathrm{~h}$. This deadline is chosen arbitrarily. In addition, surgery is performed in the case of intoxication or ileus. Our results show that our arbitrarily chosen cutoff point of $48 \mathrm{~h}$ did not entail any significant difference in outcome. Performing surgery in all body packers admitted to the hospital is not desirable. We prefer a non-invasive treatment of body packers considering the significant morbidity in body packers who underwent surgery in our study (wound infection and fascial dehiscence, both 16\%).

Mortality in our study was $2 \%$, less than a high mortality of $56 \%$ described in the early days of the treatment of body packers $[5,6,11]$. All three cases of mortality in our study required cardiopulmonary resuscitation at presentation in our emergency department. All three cases were due to intoxication by a ruptured packet, despite emergency laparotomy in two of them. All other patients, including all conservative treated patients, survived. Therefore, concerns about mortality in conservatively treated patients appears unfounded.

In 17 of the $64(27 \%)$ patients, drug packets with bad package material were found when performing surgery. In 14 patients, bad quality (e.g., loosened package material found during surgery) of the drug packets did not lead to death of those patients. One patient with bad package material developed a wound infection. This wound infection was not significant $(p=0.18)$. Bad package material was found in none of the patients with fascial dehiscence or anastomotic leakage. According to our results, bad package cannot be seen as a predictor of any surgical complication.

Furthermore, there is no consensus in the best method for removing the drug packets. Beck et al. [15] recommend performing a single enterotomy with milking of the packets toward the enterotomy. Milking only from the proximal small bowel toward retrieving them from the rectum is recommended by Utecht et al. [16]. An advantage of a single enterotomy is the reduced risk of a anastomose leakage. Disadvantage is the necessity of milking the drug packets toward the enterotomy, which can cause intestinal mucosal damage end therefore an enlarged chance of perforation. On the other hand, multiple incisions of widespread packets throughout the stomach, intestine, and colon are recommended by Lancashire et al. [17]. Disadvantage of multiple enterotomies is a higher risk of anastomose leakage, but on the other hand, performing multiple incisions needs less milking. In our study, $21(30 \%)$ patients who underwent surgery had a single incision in the stomach, intestine, or colon. Multiple incisions were performed in $35(54 \%)$ patients. In eight $(16 \%)$ patients, other surgery was performed. It is unknown if milking drug packets can cause or worsen leakage of the potentially toxic drug from a packet [1]. Review of the medical records did not reveal any patients who passed packets per annum after surgery, e.g., had residual packets.

In the group of body packers who underwent a laparotomy, there was one patient with only one drug packet in the stomach for $>48 \mathrm{~h}$. We tried to remove this packet endoscopically, but this procedure was unsuccessfully. Patient underwent surgery for removal by gastrotomy of this packet. Endoscopic removal of drug packets remains controversially. Some authors do not recommend this because of the risk of rupture during the procedure $[11,18]$. Others state that endoscopic removal is safe based on their own study results [19]. Removal of packets by gastroscopy in patients who require intubation due to intoxication is extra difficult because of the position of the endotracheal tube. Furthermore, patients with signs of intoxication are often very agitated.

There is little information in the literature on the incidence of postoperative wound infections and fascia dehiscence after surgery for body packing. The percentage of wound infection in our study group was $16 \%$; compared to the literature, this is less than the incidence of $32 \%$ after surgery for body packing reported by De Beer et al. [10]. Possibly, these wound infections are due to the fact that these wound are contaminated by the drug packets. Our study group was also compared to larger studies including elective abdominal surgery. Our incidence of wound infection of $16 \%$ is also $<22 \%$ described by Romy et al. for elective colon surgery [20] and also less than the incidence of $33 \%$ described by Cheung et al. for obstructing left-sided colon cancer [21]. The percentage of fascia dehiscence in our study group was

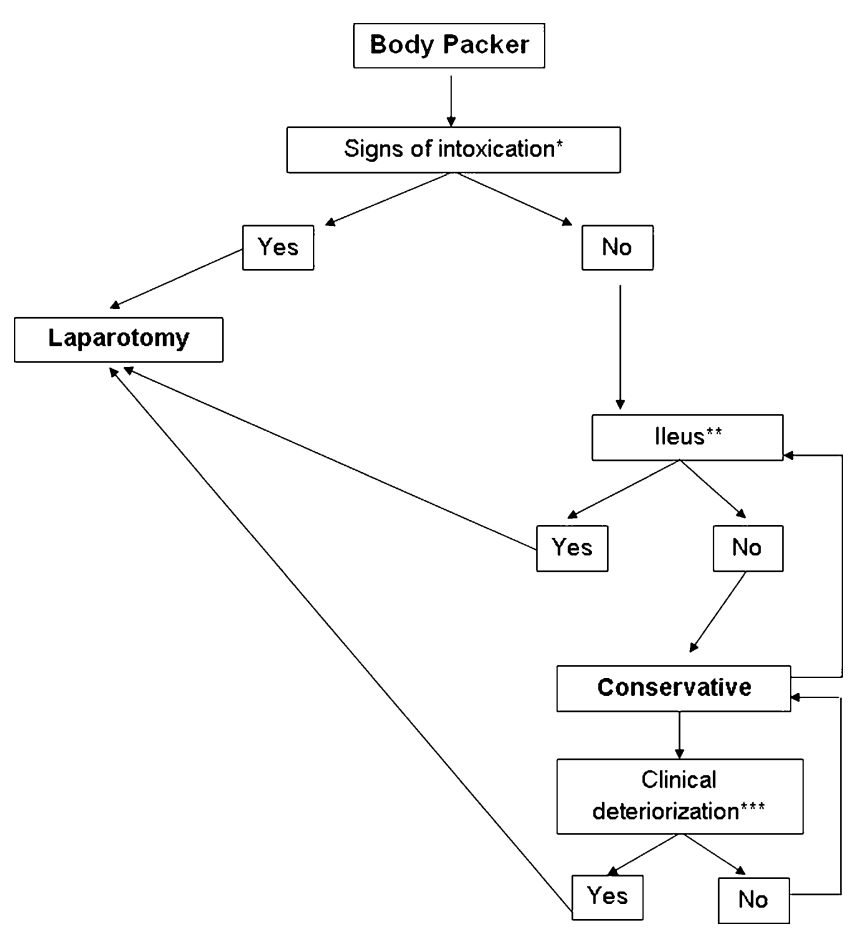

Fig. 2 Algorithm for treatment of body packers. Single asterisk Cardiopulmonary resuscitation, tachycardia of $100>$ min, agitation, systolic blood pressure $>120 \mathrm{mmHg}$, seizures. Double asterisk Distended small bowel of $>5 \mathrm{~cm}$ confirmed by plain film or CT of the abdomen. Triple asterisk Clinical deteriorization: development of signs of intoxication or sepsis 
$16 \%$, which is high compared to the study performed by De Beer et al. [10], who reported a percentage of $3 \%$. We would expect a lower percentage of fascia dehiscence because our study group consisted mostly out of young adults with a strong abdominal fascia. Furthermore, the percentage of anastomotic leakage was higher in our study (6\% compared to $1 \%)$. Consequently, the percentage of relaparotomy (17\%) was higher compared to $4 \%$ described by De Beer et al. [10].

We developed an algorithm for the treatment in body packers (Fig. 2). Body packers admitted to a hospital should first be screened for signs of intoxication. If there is any suspicion of intoxication, a laparotomy should be performed. In the absence of intoxication, the next step is to rule out the presence of an ileus. In case of an ileus, also a laparotomy should be performed. Body packers without signs of intoxication and without an ileus can then be treated conservatively. We administer electrolyte lavage solution to speed up the passage of the packets. During this conservative treatment, patients should be frequently controlled. If patients develop clinical deterioration, such as signs of intoxication or sepsis emergency laparotomy, should be performed. If a patient is treated conservatively and he or she is having stools in which drug packets with bad package material are found, the threshold for surgery should be lowered compared to stools with normal quality of packets. Doubtful in conservative treatment is the need for hospital admission. A frequently controlled patient can be treated on ambulatory basis [22]. However, immediate (re-)admission is recommended with any significant change in the symptoms of the patient. Therefore, the body packer should be strictly instructed to recognize these alarm symptoms.

This algorithm is currently used in our emergency department. To investigate the efficiency of this algorithm, further studies should be performed.

We conclude that body packers with proven drug packets in the stomach for $>48 \mathrm{~h}$ can be treated conservatively, provided that any signs of intoxication are absent. Therefore, we recommend that surgery should only be performed in body packers with signs of intoxication or ileus and to subject all other patients to conservative treatment.

\section{Conflicts of interest None.}

Open Access This article is distributed under the terms of the Creative Commons Attribution Noncommercial License which permits any noncommercial use, distribution, and reproduction in any medium, provided the original author(s) and source are credited.

\section{References}

1. Silverberg D, Menes T, Kim U (2006) Surgery for "body packers"- a 15-year experience. World J Surg 30:541-546

2. Mebane C, DeVito JJ (1975) Cocain intoxication: a unique case. J Fla Med Assoc 62:19-20

3. Booker RJ, Smith JE, Rodger MP (2009) Packers, pushers and stuffers - managing patients with concealed drugs in UK emergency departments: a clinical and medicolegal review. Emerg Med J 26:316-320

4. Traub SJ, Hoffman RS, Nelson LS (2003) Body packing - the internal concealment of illicit drugs. N Engl J Med 349:25192526

5. McCarron MM, Wood JD (1983) The cocaine 'body packer' syndrome. Diagnosis and treatment. JAMA 250:1417-1420

6. Sinner WN (1981) The gastrointestinal tract as a vehicle for drug smuggling. Gastrointest Radiol 6:319-323

7. Suarez CA, Arango A, Lester JL III (1977) Cocaine-codom ingestion. Surgical treatment. JAMA 238:1391-1392

8. Wetli CV, Mittlemann RE (1981) The "body packer syndrome"toxicity following ingestion of illicit drugs packaged for transportation. J Forensic Sci 26:492-500

9. Goertemoeller S, Behrman A (2006) The risky business of body packers and body stuffers. J Emerg Nurs 32:541-544

10. de Beer SA, Spiessens G, Mol W et al (2008) Surgery for body packing in the Caribbean: a retrospective study of 70 patients. World J Surg 32:281-285

11. van Geloven AA, van Lienden KP, Gouma DJ (2002) Bodypacking - an increasing problem in The Netherlands: conservative or surgical treatment? Eur J Surg 168:404-409

12. Bulstrode N, Banks F, Shrotria S (2002) The outcome of drug smuggling by 'body packers' - the British experience. Ann R Coll Surg Engl 84:35-38

13. Caruana DS, Weinbach B, Goerg D et al (1984) Cocaine-packet ingestion. Diagnosis, management, and natural history. Ann Intern Med 100:73-74

14. Veyrie N, Servajean S, Aissat A et al (2008) Value of a systematic operative protocol for cocaine body packers. World J Surg 32:1432-1437

15. Beck NE, Hale JE (1993) Cocaine 'body packers'. Br J Surg 80:1513-1516

16. Utecht MJ, Stone AF, McCarron MM (1993) Heroin body packers. J Emerg Med 11:33-40

17. Lancashire MJ, Legg PK, Lowe M et al (1988) Surgical aspects of international drug smuggling. Br Med J (Clin Res Ed) 296:1035-1037

18. Miller JS, Hendren SK, Liscum KR (1998) Giant gastric ulcer in a body packer. J Trauma 45:617-619

19. Mandava N, Chang RS, Wang JH et al (2011) Establishment of a definitive protocol for the diagnosis and management of body packers (drug mules). Emerg Med J 28:98-101

20. Romy S, Eisenring MC, Bettschart Vet al (2008) Laparoscope use and surgical site infections in digestive surgery. Ann Surg 247:627-632

21. Cheung HY, Chung CC, Tsang WW et al (2009) Endolaparoscopic approach vs conventional open surgery in the treatment of obstructing left-sided colon cancer: a randomized controlled trial. Arch Surg 144:1127-1132

22. Beckley I, Ansari NA, Khwaja HA et al (2009) Clinical management of cocaine body packers: the Hillingdon experience. Can J Surg 52:417-421 